\title{
Flaking of PEEK under one-point rolling contact fatigue using $\mathrm{Al}_{2} \mathrm{O}_{3}$ ball
}

\author{
Hitonobu KOIKE ${ }^{1 a}$, Genya YAMAGUCHI ${ }^{2}$, Koshiro MIZOBE ${ }^{2}$, and Katsuyuki KIDA ${ }^{2}$ \\ ${ }_{1}^{1}$ University of Miyazaki, 1-1 Gakuen Kibanadai-nishi, Miyazaki, 889-2192, Japan \\ ${ }^{2}$ University of Toyama Gofuku 3190, Toyama, 930-8555, Japan
}

\begin{abstract}
The growth of flaking as tribological fatigue failure in PEEK was investigated through the one-point type rolling contact fatigue test between a machined PEEK polymer shaft and an alumina bearing's ball. Due to Hertzian contact of cyclic compressive stress, the subsurface fatigue cracks in the PEEK shaft propagated in rolling and axial directions. When the rolling fatigue life of the PEEK shaft reached $10^{6}$ fatigue cycles, many narrow angled cracks occurred in the near-surface of the rolling track without flaking. On the other hand, when the flaking ocuurred on the PEEK shaft before $10^{6}$ fatigue cycles, semicircular surface and subsurface crack propagations were observed. From these observations, it was found that micro-flaking occurred due to the linkages between subsurface -and surface cracks. Flakingdeveloped due to the accumulation of these micro-flakings.
\end{abstract}

\section{Introduction}

Lightweight function parts using premium plastics are extended in various mechanical elements under special chemical environments [1-2]. Polymer bearings or gears as precision-machined custom functional parts are suitable for assembly robots, agricultural devices, applications related to chemical and medical food [3]. Friedrich et al. [4] stated that the most important points of the polymer component design are mechanical stresses and environments.

Poly-ether-ether-ketone (PEEK) has high chemical resistance, self-lubrication ability, no degradation risk in salt water, and non-electrical conductivity. Researchers investigated tribological failures of PEEK materials for frictional parts used under rolling contact fatigue (RCF) [3,5-7]. Flaking as tribological fatigue failure causes noise, vibration, or alignment error in components, which is an important quality problem for products. Marshek examined failure in plastic bearings, and explained flaking as material breaking loose from the surface in the form of shallow flakes [5]. Briscoe stated that a fatigue process with repeated stress cycles could involve crack propagation. [6]. Avanzini et al. reported that in RCF between a PEEK roller and a steel disk micro-pitting and transversal crack on the rolling surface of the roller edge occurred due to tangential stress [7]. Dearn et al. reported that the location of the maximum shear stress depended on the friction condition and was related with the fracture of PEEK polymer gears [8]. Flaking was related to the internal fatigue cracks which were caused by cyclic shear stress below the contact surface [9]. Koike et al. stated that in the RCF of the PEEKalumina ball bearings with an artificial pit, the subsurface fatigue crack ocuured at 100-200 um depth from the contact surface. This means that the internal fatigue crack from an artificial pit was influenced by internal shear stress [9]. As Young's moduli of polymers are significantly lower than that of common metals or ceramics, internal stress and elastic deformation of friction area of polymers are greatly influenced by cyclic Hertzian contact. Therefore, the behavior of the internal fatigue crack propagation in the machined PEEK elements is not well understood. The practical research on PEEK's tribological fatigue fracture in application of PEEK and ceramic parts is investigated in few studies [9-11].

Kida et al. performed RCF test using $\mathrm{Si}_{3} \mathrm{~N}_{4}$ balls and $\mathrm{Si}_{3} \mathrm{~N}_{4}$ plates with an artificial pit, and investigated the fatigue crack propagation under the rolling track [12]. They proposed that the subsurface crack propagation depended on the mode II or mode III crack propagation after the surface crack propagation in sliding-rolling contact [12].

In this study, in order to explore the flaking mechanism under rolling contact between machined PEEK shaft and alumina ball, one-point Rolling Contact Fatigue (RCF) tests were performed. The internal fatigue crack propagation in early stages of the flaking was observed.

\section{Experimental procedure}

\subsection{PEEK shaft specimens}

The machined PEEK shaft with a $290 \mathrm{~mm}$ length and a $17 \mathrm{~mm}$ diameter was used for the one-point RCF test (Fig.

\footnotetext{
a corresponding author: koikeh@cc.miyazaki-u.ac.jp
} 
1). The PEEK material grade was $450 \mathrm{G}$ in VICTREX ${ }^{\mathrm{TM}}$. An alumina ball with $9.525 \mathrm{~mm}$ (3/8 inch) diameter was used as a counter contact part in the one-point RCF test. To estimate the contact stress between the shaft and the ball, Young moduli of PEEK (3.5 GPa) and alumina (360 $\mathrm{GPa})$ were used. After the grinding process on the PEEK shafts, the average roughness $\left(R_{a}\right)$ on the surface of the shaft was $0.69 \sim 1.10 \mu \mathrm{m}$.

\subsection{One-point rolling contact fatigue test}

The RCF tests were performed by using the one-point radial loading machine as shown in Figure 1 [13]. The alumina ball contacted the PEEK shaft specimen under oil lubricant condition. Kinematic viscosity of the lubricant oil was $46 \mathrm{~mm}^{2} / \mathrm{sec}$ at $40{ }^{\circ} \mathrm{C}$. Radial load was applied to the PEEK shaft, while rotating by a DC motor. The rolling track was concentrated on only one line on the PEEK shaft under a radial load. This means that we can observe easily the damage zone of the parts under cyclic contact stress. In the one-point RCF tests, the contact area between the PEEK shaft and the alumina ball was ellipse shape due to Hertzian elasticity contact (detail A in Fig. 1b). The maximum Hertzian contact stress $P_{\max }$ values and contact ellipse diameter values were shown in Table 1. The test conditions of radial load and rotation speed were 90-360 N and $1200 \mathrm{rpm}$, respectively. They were the same as our previous works $[9,14]$. This is because the present tests were done in order to focus on the details of the fatigue fracture origin/propagation of the one-point RCF test. The surface velocity of the PEEK shaft was estimated as $1068 \mathrm{~mm} / \mathrm{sec}$. The minimum film thickness $\left(h_{\min }\right)$ in the point contact at $120 \mathrm{~N}$ was caluculated by Hamrock and Dowson's equations [15]. The $h_{\min }$ was $0.142 \mu \mathrm{m}$, which corresponded to the mix lubrication. The one-point RCF tests were continued until $4.5 \times 10^{6}$ fatigue cycles or fatigue failure. The flaking growth and fatigue crack propagation in the tested PEEK shaft specimens were observed by laser confocal microscopy (Fig. 2a and 2b). The PEEK shafts after the RCF tests were cut along the rolling contact track. The cross-sections of the rolling track were polished, and the growth of flaking was arranged by using $2.5 \mathrm{D}$ layer o b s e r vation method ( Fig. $2 \mathrm{c}$ ).

\section{Experimental results and discussion}

\subsection{Contact surface of PEEK shaft under one- point RCF}

Figure 3 shows microscope images of the rolling track of the PEEK shaft after the one-point RCF tests. The higher the radial load, the larger the flaking size. As shown in Fig. 3(b), semicircular surface cracks like 'fishscale shape' were observed near the flaking. The rolling direction length $\left(L_{r o}\right)$ of flaking was longer than the axial direction width $\left(W_{a x}\right)$. This means that in flaking on the rolling track of the PEEK shaft the fatigue cracks propagated faster toward the rolling direction than toward the axial direction. When radial load was $360 \mathrm{~N}$, the delamination occurred on whole rolling track (Fig. 3(d)). Therefore, $L_{r o}$ and $W_{a x}$ could not be measured. It was thought that subsurface cracks propagated due to internal shear stress. Table 2 shows the

\begin{tabular}{lcccc}
\multicolumn{5}{c}{ Table 1. Maximum contact pressure and contact ellipse diameter values. } \\
\hline $\begin{array}{l}\text { Radial applied load, } \\
\boldsymbol{Q}[\mathbf{N}]\end{array}$ & $\begin{array}{c}\text { Maximum contact pressure, } \\
\boldsymbol{P}_{\max }[\mathbf{M P a}]\end{array}$ & $\begin{array}{c}\text { Long diameter, } \\
\boldsymbol{D}_{\boldsymbol{L}}[\mathbf{m m}]\end{array}$ & $\begin{array}{c}\text { Short diameter, } \\
\boldsymbol{D}_{\boldsymbol{S}}[\mathbf{m m}]\end{array}$ \\
\hline 90 & 274 & 0.918 & 0.684 \\
120 & 301 & 1.011 & 0.753 \\
240 & 380 & 1.273 & 0.949 \\
\hline
\end{tabular}

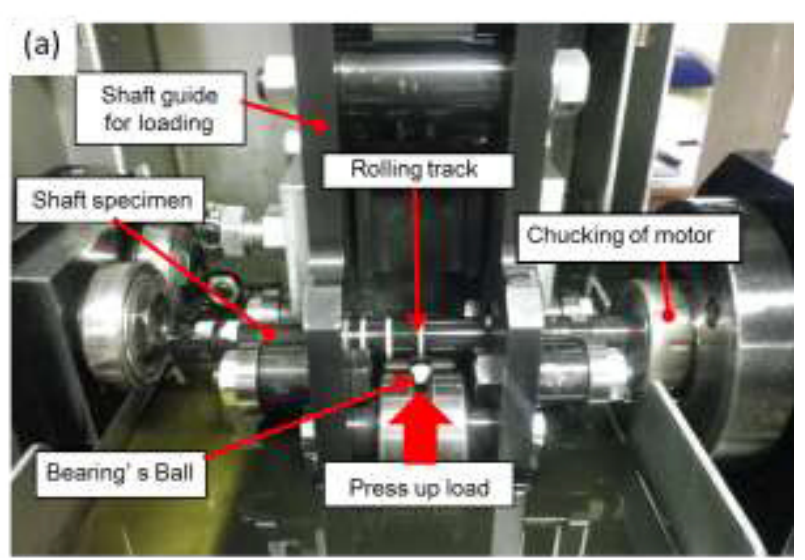

(b)

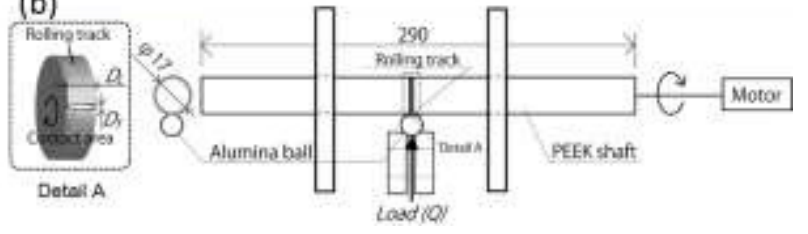

Fig. 1. One-point radial loading test machine; (a) photo image of one-point RCF test, (b) illustration of test specimen.

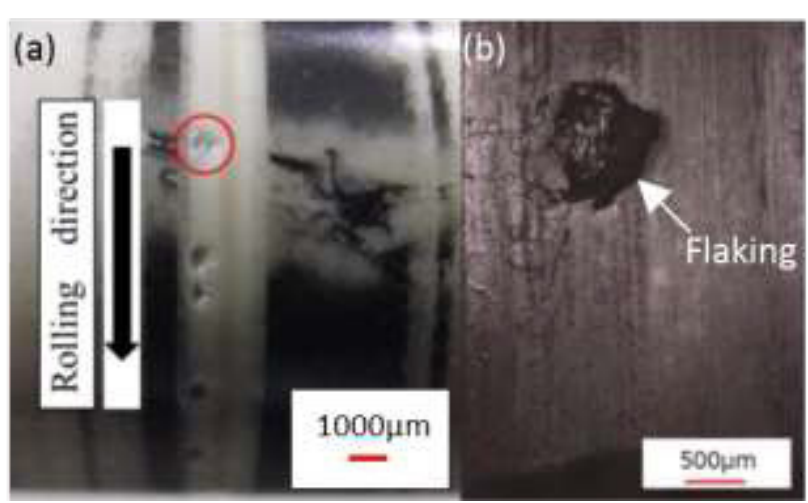

(c)

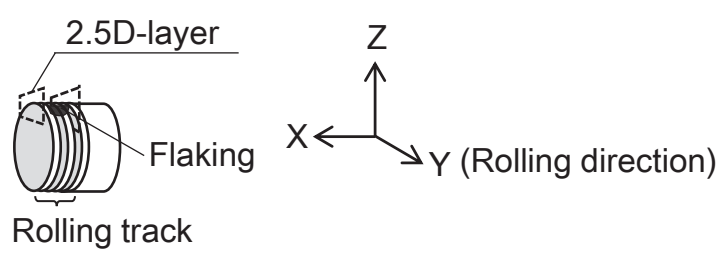

Fig. 2. Test specimen after one-point RCF test; (a) flaking on the rolling track, (b) close-up of flaking, (c) illustration of 2.5D layer observation (in Fig. 5). 
flaking size at $1200 \mathrm{rpm}$. This result suggests that the higher the radial load, the shorter the fatigue life. The flaking at $240 \mathrm{~N}$ load occurred in early operation term compared to at $90 \mathrm{~N}$ load because the crack propagation at high applied load was faster than that at low load.

\subsection{Crosssection of PEEK shaft under one-point RCF}

Figure 4 shows 2.5D layer images of the crosssection of the flaking area along rolling direction at $1.9 \times 10^{6}$ fatigue cycles under a load of $240 \mathrm{~N}$. The maximum depth of the flaking was approximately $215 \mu \mathrm{m}$, and the downward branch subsurface crack propagated along the rolling direction (Fig. 4(\#1)). The flaking bottom gradually rose upward along axial direction (Fig. 4(\#1) (\#4)). Additionally, the downward branch subsurface crack from the flaking bottom was observed at $268 \mu \mathrm{m}$ depth as shown in Fig. 4(\#5). This result shows that the downward branch subsurface crack influenced the growth of flaking.

Figure 5 shows 2.5D layer images of the crosssection of the flaking at $2.9 \times 10^{4}$ fatigue cycles under $240 \mathrm{~N}$ radial load. As shown in Fig. 5(\#2), downward branch subsurface crack was observed below the $2^{\text {nd }}$ flaking. By the propagation of subsurface cracks, the first flaking merged with the second (Fig. 5(\#2 and \#3)). At this time the maximum depth of the flaking was $534 \mu \mathrm{m}$. As shown in figure 5(\#8), the flaking grew due to the fusion of subsurface crack and surface crack.

Figure 6 shows the close-up of the flaking origin in the nearsurface of the PEEK shaft. In early stage of flaking, micro-pitting or micro-flaking occurred in the nearsurface of the rolling track. The first micro-flaking occurred within $200 \mu \mathrm{m}$ depth from the rolling track surface due to the fusion of some subsurface cracks (Fig. $6 \mathrm{~b})$. It was found that flaking grew gradually with the linkages of the micro-flakings.

Figure 7 shows the profiles of the maximum depths of the flakings at $120 \mathrm{~N}$. Test \#2 corresponds to the flaking in Figure 4. In the profiles, valley points were observed at flaking bottoms. This means that the flaking gradually grows due to the accumulation of small (micro) flakings.

Figure 8 shows the microscope image of the crosssection around non-flaking area on the rolling track of the PEEK shafts at $1.9 \times 10^{6}$ cycles under $120 \mathrm{~N}$. Many narrow angled cracks were observed on the subsurface. The narrow angled cracks propagate along the rolling direction at around $200 \mu \mathrm{m}$ depth from the shaft surface. These cracks caused micro-flaking.

Table 2. Flaking size of the PEEK specimens.

\begin{tabular}{|c|c|c|c|c|c|}
\hline $\begin{array}{l}\text { Test } \\
\text { number }\end{array}$ & $\begin{array}{c}\text { Radial load } \\
Q[\mathrm{~N}] \\
\end{array}$ & $\begin{array}{l}\text { Rolling direction } \\
\text { length, } L_{r o}[\mathrm{~mm}]\end{array}$ & $\begin{array}{c}\text { Axial direction } \\
\text { width, } W_{a x}[\mathrm{~mm}]\end{array}$ & $\begin{array}{c}\text { Maximum depth of } \\
\text { flaking }[\mathrm{mm}]\end{array}$ & $\begin{array}{c}\text { Fatigue cycles } \\
N \text { [cycles] }\end{array}$ \\
\hline 1 & 90 & 0.759 & 0.450 & 0.154 & $4.5 \times 10^{6}$ \\
\hline 2 & 120 & 0.866 & 1.077 & 0.215 & $1.9 \times 10^{6}$ \\
\hline 3 & 120 & 1.465 & 1.227 & 0.413 & $4.6 \times 10^{5}$ \\
\hline 4 & 120 & 1.510 & 0.930 & 0.610 & $3.6 \times 10^{5}$ \\
\hline $5^{\text {[ref. 11] }}$ & 120 & 2.039 & 1.416 & 0.682 & $4.1 \times 10^{5}$ \\
\hline 6 & 240 & 1.390 & 1.270 & 0.534 & $2.9 \times 10^{4}$ \\
\hline 7 & 240 & 1.392 & 1.481 & 0.479 & $3.0 \times 10^{4}$ \\
\hline
\end{tabular}
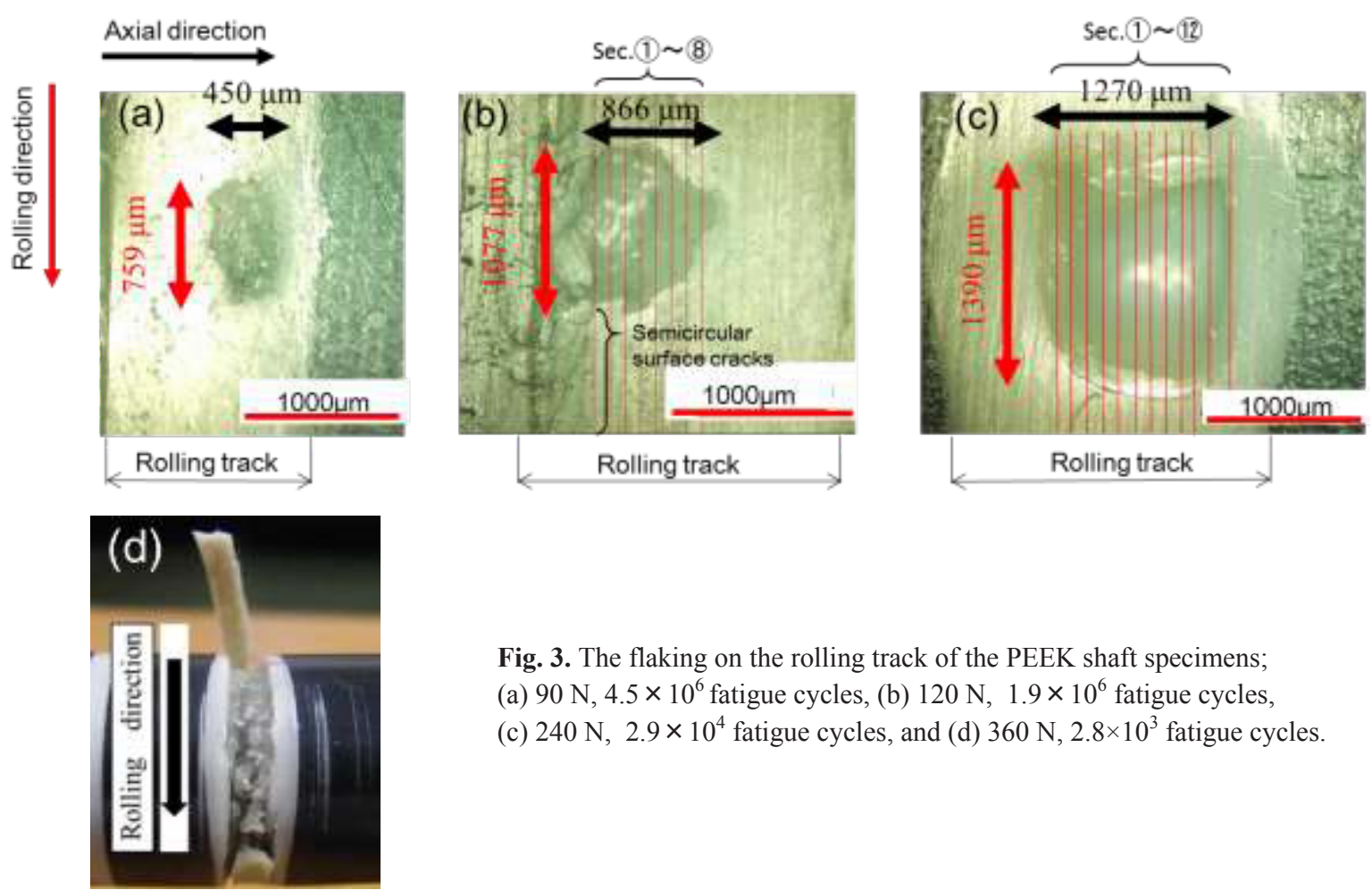

Fig. 3. The flaking on the rolling track of the PEEK shaft specimens; (a) $90 \mathrm{~N}, 4.5 \times 10^{6}$ fatigue cycles, (b) $120 \mathrm{~N}, 1.9 \times 10^{6}$ fatigue cycles, (c) $240 \mathrm{~N}, 2.9 \times 10^{4}$ fatigue cycles, and (d) $360 \mathrm{~N}, 2.8 \times 10^{3}$ fatigue cycles. 

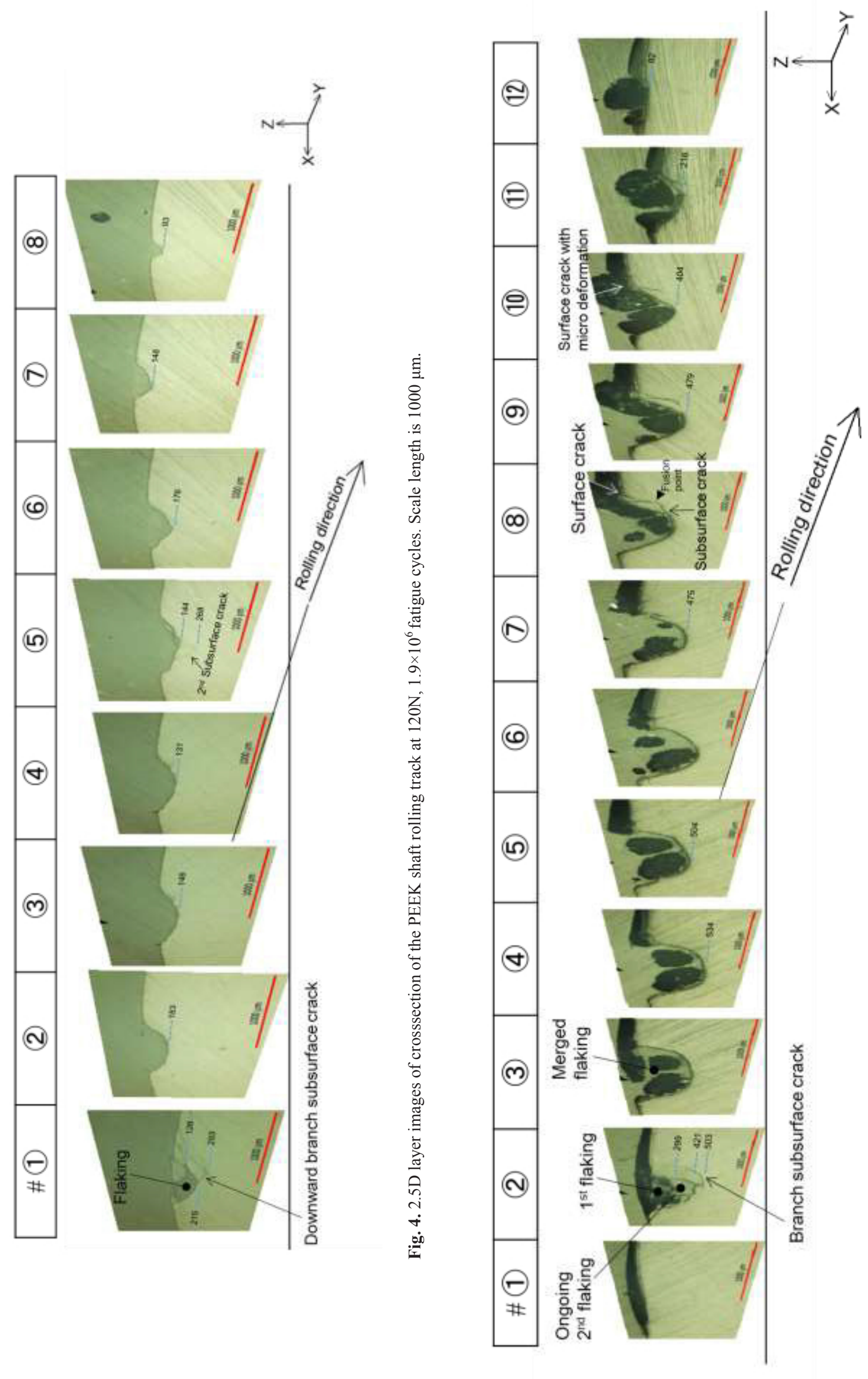

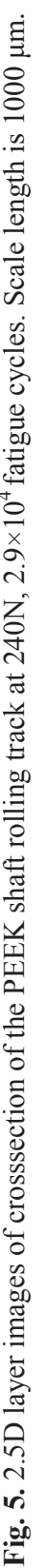




\section{Micro-pitting}
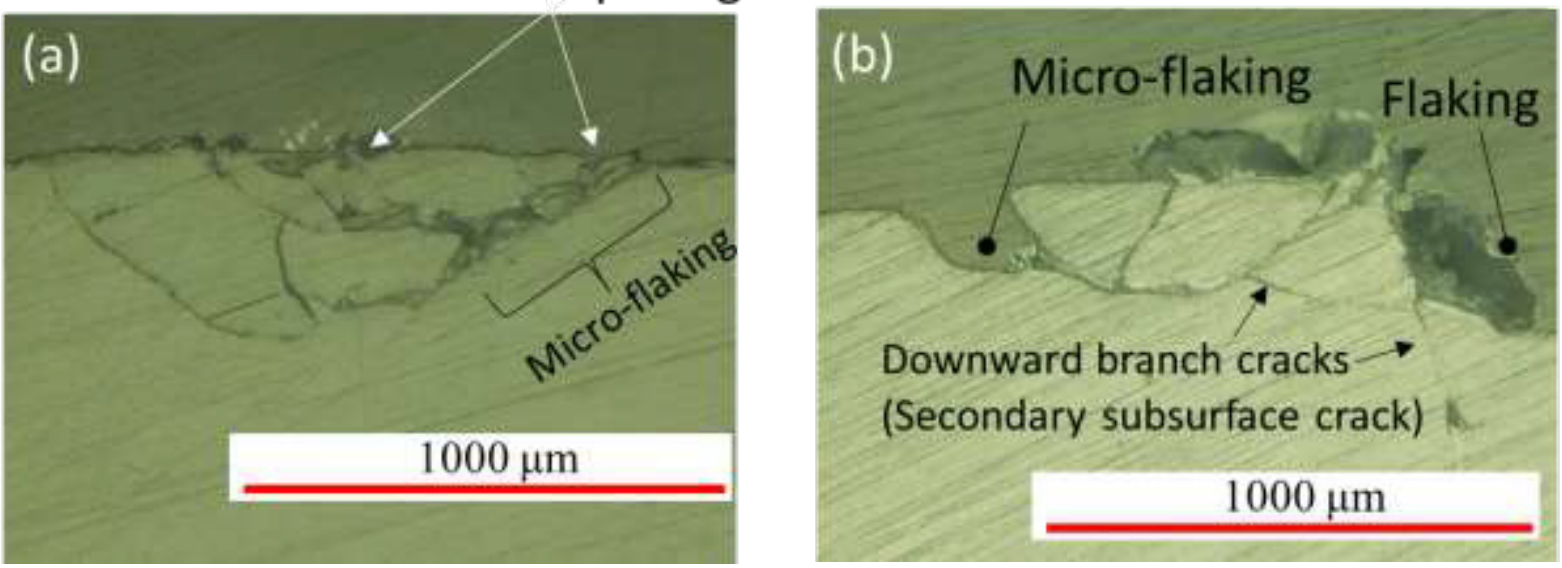

Fig. 6. Detail of the flaking origin at $120 \mathrm{~N}$ at $1.9 \times 10^{6}$ fatigue cycles; (a) micro-pitting, (b) micro-flaking and branch crack.

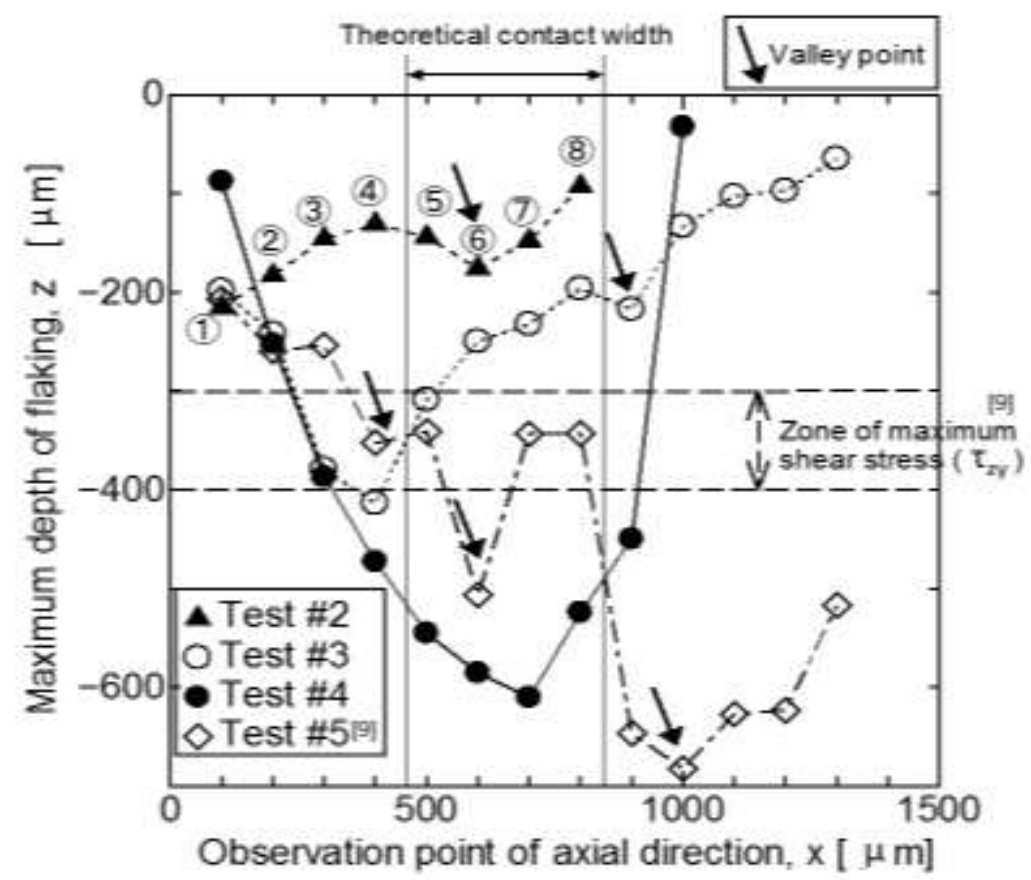

Fig. 7. Maximum depth of flaking of the PEEK shaft at $120 \mathrm{~N}$.

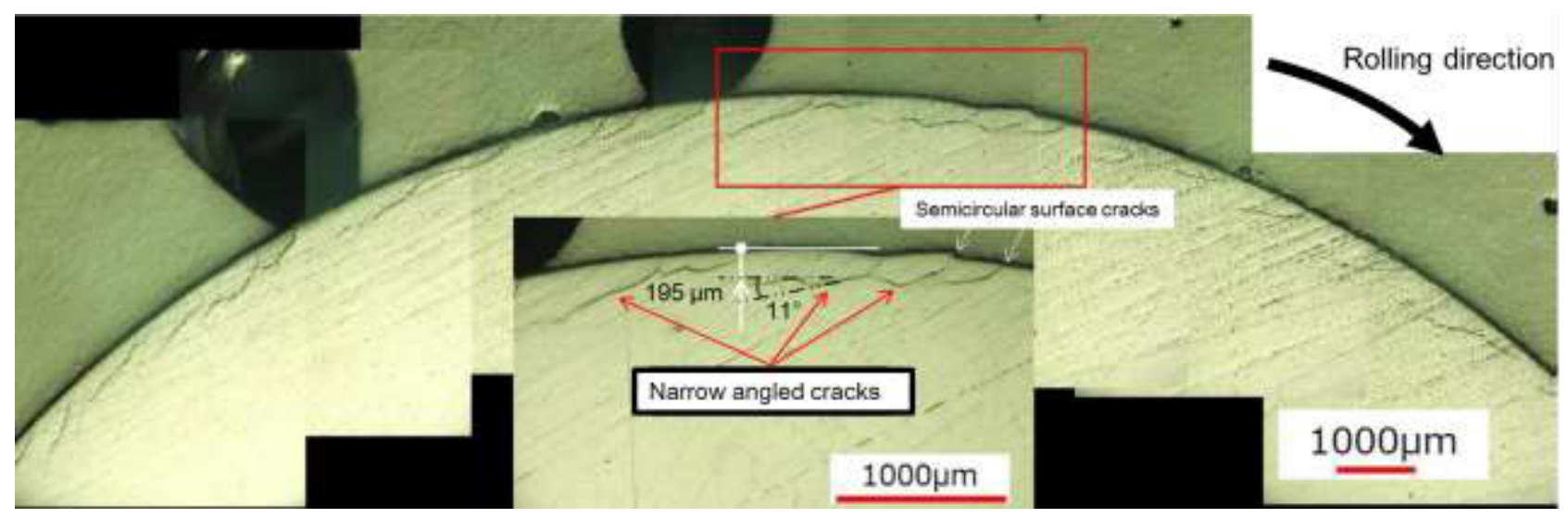

Fig. 8. Cross-section of near-surface cracks before fatigue fracture at $120 \mathrm{~N}\left(1.9 \times 10^{6}\right.$ cycles $)$. 


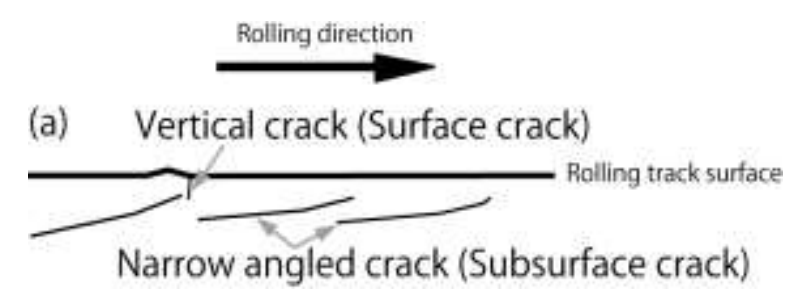

(b)
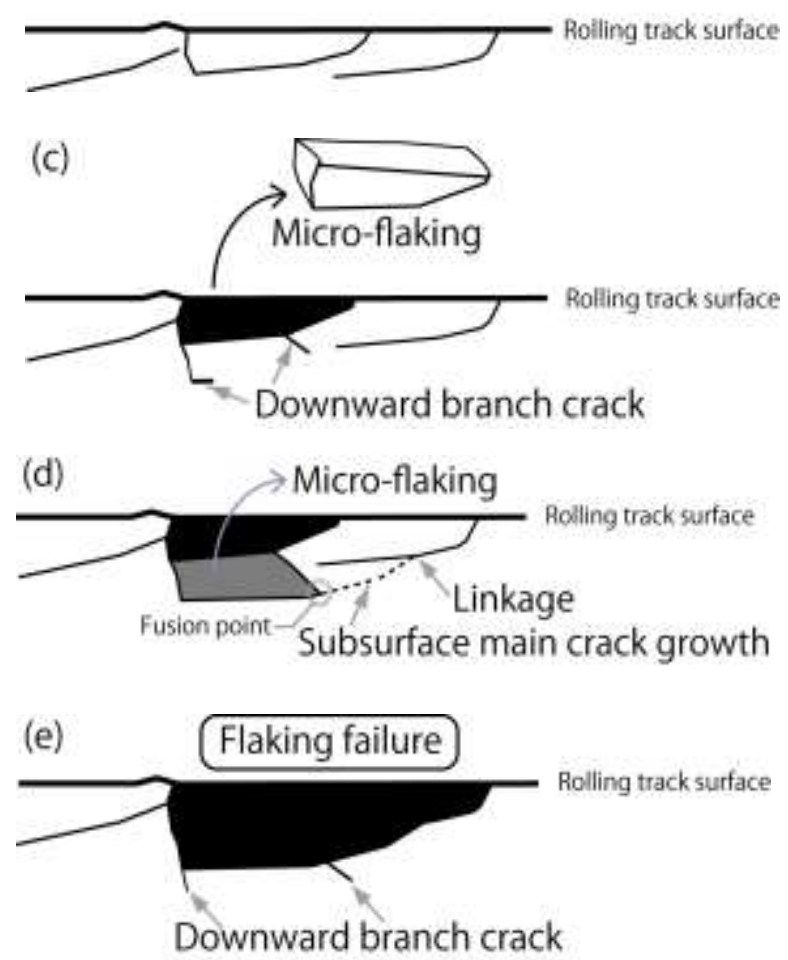

Fig. 9. Illustration of the flaking growth of PEEK shaft under one-point rolling contact fatigue.

\subsection{Growth of flaking of PEEK shaft under one- point RCF}

Figure 9 shows the flaking process near PEEK shaft surface. The flaking process is as follows:

(a) Narrow angled cracks occur near the rolling track surface due to internal shear stress.

(b) When the narrow angled cracks merge with each other, micro-flaking occurs.

(c) Downward branch crack propagates from the subsurface crack.

(d) Due to growth and fusion of subsurface cracks, secondally micro-flaking occurs.

(e) Subsurface main crack merges with other subsurface cracks (i.e. narrow angled cracks). Accumulation of the micro-flaking results the flaking failure.

\section{Conclusion}

In order to explore the flaking mechanism of PEEK shafts under rolling contact against alumina ball, one- point rolling contact fatigue (RCF) tests were carried out at $1200 \mathrm{rpm}$ rotaion speed. The important results obtained from this work are summarized as follows:

(1) The length of the flaking was larger than the width. The subsurface crack propagated rapidly in rolling direction compared to in axial direction.

(2) Accumulation of micro-flaking results in the flaking growth. There were three types of subsurface cracks during flaking growth; narrow angled crack, downward branch crack, and main subsurface crack. The downward branch crack occurs from the subsurface crack, and propagates into the depth direction of PEEK shaft.

(3) Micro-flaking occurs due to the linkage of subsurface cracks and narrow angled cracks (and/or another subsurface crack) during the flaking process.

This research work is financially supported by JSPS KAKENHI Grant Number JP16K06042.

\section{References}

1. T. A. Stolarski, Adv. Comp. Trib.edited by K. Friedrich, Elservier, Chapter 17, (1993)

2. K. Friedrich, G. Theiler and P. Klein, In: SinhaSK, BriscoeBJ, editors. Polymer Tribology, (London UK: Imperial College Press, 2009)

3. M. Harrass, K. Friedrich, and A. A. Almajid, Trib. Int'l, 43, 635-646 (2010)

4. K.Friedrich, Z. Lu and A. M. Hager, Theo Appl Fract Mech, 19, 1-11 (1993)

5. K. M. Marshek, Wear, 52, 141-146 (1979)

6. B.J. Briscoe, The tribology of Polymer Composite Materials, Advanced in Composite Tribology edited by K. Friedrich, Elservier, (1993)

7. A. Avanzini, G.Donzella, A.Mazzù, C.Petrogalli, Trib. Int'l, 157, 22-30 (2013)

8. K. D. Dearn, S. N. Kukureka, and D. Walton, In: SinhaSK, BriscoeBJ, editors. Polymer Tribology, (London UK: Imperial College Press, 2009)

9. H. Koike, K. Kida, T. Honda, K. Mizobe, S. Oyama, J. Rozwadowska, Y. Kashima, and K. Kanemasu, Adv. Mat. Res., 566, 109-114 (2012)

10. H. Koike, K. Kida, E. C. Santos, J. Rozwadowska, Y. Kashima, K. Kanemasu, Trib. Int'1, 49, 30-38 (2012)

11. H. Koike, G. Yamaguchi, K. Mizobe, Y. Kashima, K. Kida, MATEC Web of Conferences, 130, 9001(2017)

12. K. Kida, K. Ogura, The Society of Materials Science, Japan, 48, 10, 1090-1094 (1999)

13. J. Rozwadowska, K. Kida, E. C. Santos, T. Honda, H. Koike, K. Kanemasu, Adv. Mat. Res.,418-420, 16131617 (2012)

14. H.Koike, K. Kida, K. Mizobe, X.Shi, S. Oyama, Y. Kashima, Trib. Int'1, 90, 77-83 (2015)

15. B. J. Hamrock and D. Dowson, J. of Lubrication Tech 98(3), 375-381 (1976) 